\title{
Cell saver physics - a review
}

\section{Fourtounas}

Department of Anaesthesiology, School of Clinical Medicine, Faculty of Health Sciences, University of the Witwatersrand, South Africa Corresponding author, email: maria.fourtounas@wits.ac.za

\section{Summary}

Cell salvage, cell saver, cell processor or autologous blood transfusion is the process of collecting a patient's blood from the surgical field, washing, filtering and transfusing it back to the same patient. There are six basic steps involved in cell salvage. Step one involves the collection of shed blood into a reservoir with an anticoagulant-saline mixture. Step two is the filtration of debris and clots. In step three, the red blood cells (RBCs) are separated from the nonerythrocyte components. This process may be likened to clothes in the washing machine. Washing with saline removes contaminants in step four and the RBCs are resuspended in saline and transferred to the reinfusion bag. Waste products are transferred into the waste bag in step five. In step six, the resuspended, washed RBCs are collected in a bag at room temperature which can be reinfused.

The functioning of the cell saver is based on Newton's First and Second Laws of Motion, where centripetal forces are generated to separate the blood components depending on their density. The denser RBCs are driven to the outer wall of the centrifuge bowl with the plasma collecting on the inside. A typical yield will retrieve 50-95.8\% RBCs with a final haematocrit of 50-70\%.

Cell savers are used in procedures with a large volume of anticipated blood loss, high risk of bleeding, low preoperative haemoglobin, in patients with rare blood groups or multiple antibodies and in some Jehovah's Witness patients.

Keywords: cell saver, centripetal force, blood reinfusion

\section{Introduction}

Cell salvage, cell saver, cell processor or autologous blood transfusion is the process of collecting a patient's blood from the surgical field, washing, filtering and transfusing it back to the same patient. ${ }^{1,2}$ Autologous transfusions can occur intraoperatively, using a cell saver, or postoperatively, using special drains.

\section{How it works}

There are six basic steps involved in cell salvage. ${ }^{1-4}$ Beneath these basic steps are the true physics principles behind the functioning of a cell salvage device.

The centrifugal bowl is the cell separation bowl. It spins around a central vertical axis and this spinning creates acceleration, commonly called the "centrifugal force". This, however, is incorrect.

Newton's Second Law of Motion states "The acceleration of an object is directly proportional to the net force acting on it and is inversely proportional to its mass. The direction of the acceleration is in the direction of the net force acting on the object." As an equation is it written as:

$$
\sum \mathbf{F}=m \mathbf{a} \quad \begin{aligned}
& \sum=\text { sum of } \\
& \mathbf{F}=\text { force } \\
& \mathbf{m}=\text { mass } \\
& \mathbf{a}=\text { acceleration }
\end{aligned}
$$

A centrifuge is a device that spins around a central vertical axis creating a large and useful force. This is described as a centrifugal force but scientifically it does not exist. It is in fact a centripetal force, and more correctly centripetal acceleration. When an object experiences uniform circular motion, it travels in a circular path at a constant speed. If one applies Newton's First and Second Laws of Motion, an object moving along a curved path has a constantly changing velocity as the direction is constantly changing. If velocity is changing, then the object is accelerating. And for an object to accelerate, a force needs to be applied to it. As the object enters a bend, its natural tendency is to continue in a straight line unless acted upon by a force. If the object follows the bend, then there is a force constantly "pulling" it inward; this is the centripetal force. ${ }^{6}$

These forces can be calculated using the following formula: ${ }^{4,6}$

$$
\mathbf{F}=m\left[\frac{\mathbf{V}^{2}}{\mathbf{r}}\right] \quad \begin{aligned}
& \mathbf{F}=\text { net force } \\
& \mathbf{m}=\text { mass }(\text { Newtons) } \\
& \mathbf{v}=\text { rotational velocity }(\mathrm{m} / \mathrm{s}) \\
& \mathbf{r}=\text { radius of rotation }
\end{aligned}
$$

The above formula indicates that increasing the mass of the object and increasing the speed, requires an increase of the force. Centrifuges are useful instruments for separating mixtures, in the cell saver this mixture is whole blood. As the centrifuge "spins", centripetal forces are generated which separate the blood components depending on their density, listed in Table $1 ;{ }^{4}$ the denser RBCs are driven to the outer wall of the centrifuge with the supernatant plasma collecting on the inside, and as the less 
dense (lighter) fraction, this is forced out the centrifuge bowl via effluent tubing to the waste bag. Within the centrifuge bowl, the radius is fixed and the densities of the components are constant; therefore the controlling variable is the rotational velocity of the bowl, the revolutions per minute (rpm). ${ }^{4}$

Table I: Density range for the constituents of blood ${ }^{4}$

\begin{tabular}{ll}
\hline Blood component & Component density range \\
\hline Plasma & $1.025-1.029$ \\
\hline Thrombocytes & $1.060-1.067$ \\
White blood cells (WBCs) & $1.065-1.090$ \\
Red blood cells (RBCs) & $1.085-1.097$ \\
\hline
\end{tabular}

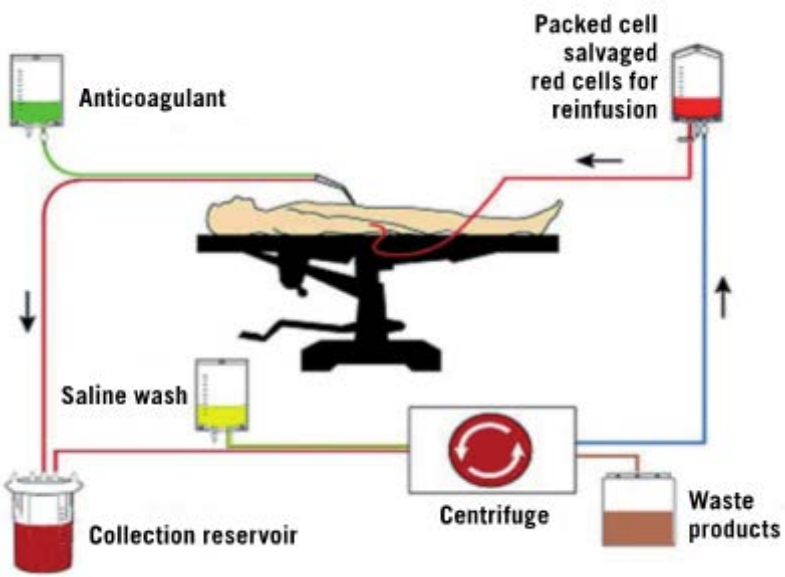

Figure 1: The "flow" of RBCs within the cell salvage system²

A

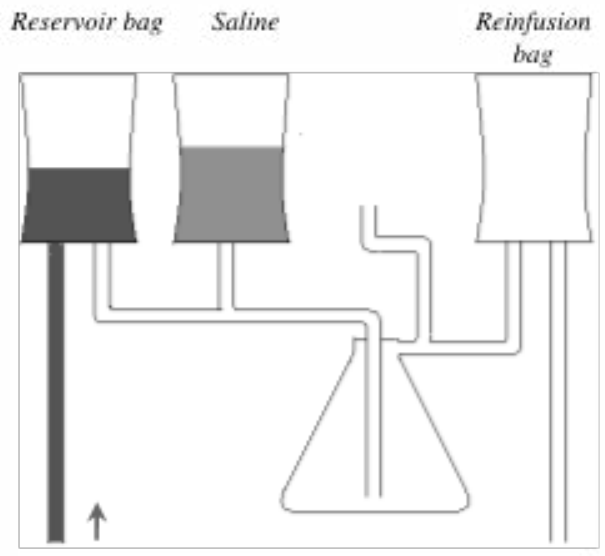

C

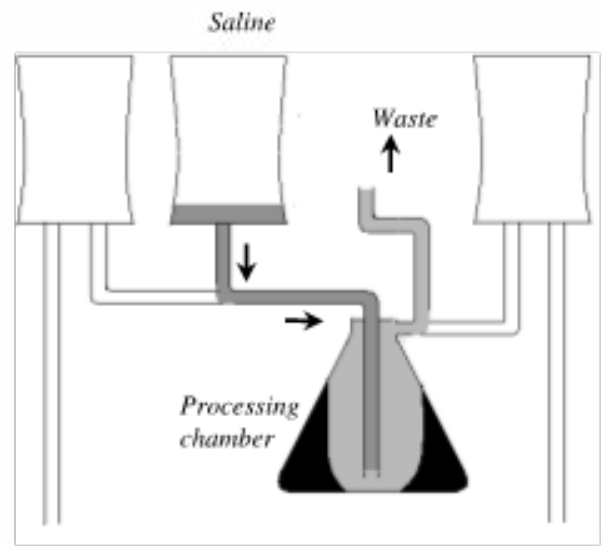

The six steps will be discussed in detail. Figure 1 provides an overall impression of the "flow" of RBCs within the entire cell salvage system. Most devices have an automatic mode where steps will take place as certain requirements are met, e.g. reservoir volume, $\mathrm{RBC}$ haematocrit in centrifuge bowl, centrifuge bowl volume. A manual mode may be selected and most of the variables altered to better suit specific settings and procedures. The collection reservoir and suction set may be used independently from the processing and reinfusion set.

Step 1: Suction/Collection of blood ${ }^{3,4,7,8}-$ Aspiration and anticoagulation assembly (Figure 2A)

Prior to collecting shed blood, $100-200 \mathrm{ml}$ of anticoagulantsaline solution is introduced into the reservoir bowl. The filter becomes wet and prevents clotting of collected blood within the reservoir. Blood is collected from the surgical field or from drains using a wide bore $(4 \mathrm{~mm})$, double lumen tubing at a low pressure $(100-150 \mathrm{mmHg}$ or $20 \mathrm{kPa}$ ) to reduce RBC damage. The level of haemolysis with salvaged blood is generally low but is dependent on the surgical suction forces and the site of suctioning - a pool of blood or surface "skimming", e.g. bleeding bone; "skimming" is associated with increased haemolysis., 3,,9,10 The double lumen tube contains an inner tube allowing for delivery of the anticoagulant to the distal end of the suction tube. This is suctioned with the blood as it is collected and reduces the risk of clotting within the suction tube. In most settings, heparin is used. The blood and anticoagulant mixture is collected in the reservoir bowl. The system is continuously anticoagulated with

B

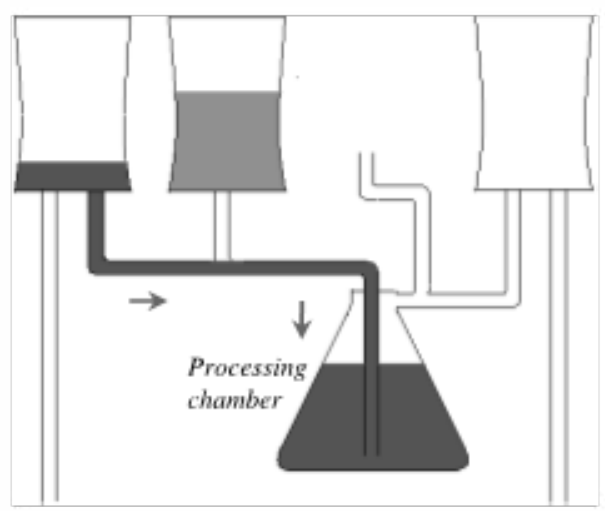

D

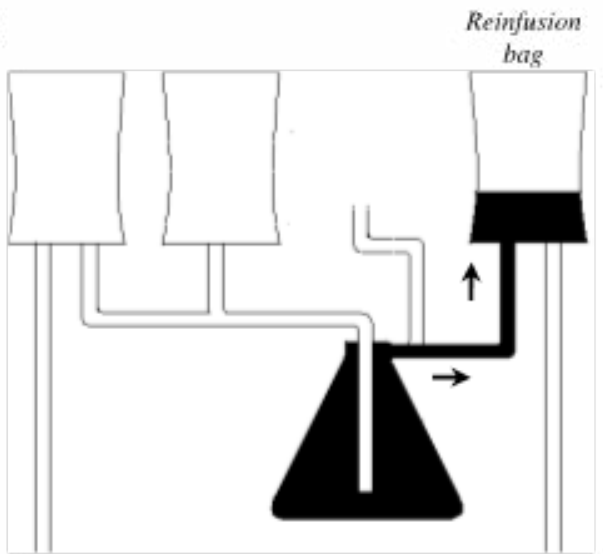


heparinised saline. The recommended solution is 25 000-30000 IU heparin in $1 \mathrm{~L} 0.9 \% \mathrm{NaCl}$, with the drip rate set at 1-2 drops per second. Citrate may also be used. Blood-soaked swabs may be washed in heparinised saline and the saline-blood mixture collected.

\section{Step 2: Filtration' (Figure 2A)}

Debris and clots are filtered from the operative site using a filter within the reservoir bowl. The filter has a pore range of 40-150 $\mu \mathrm{m}$.

\section{Step 3: Separation ${ }^{1,3,7}$ (Figure $2 B$ and $2 C$ )}

The harness consists of three lines: red-coded tubing connects to the reservoir bowl and drains contents into the centrifuge; yellow-coded tubing connects the saline wash to the centrifuge; blue-coded tubing connects the centrifuge to the reinfusion bag. A clear (non-colour coded) effluent tube connects the centrifuge to the waste bag.

Once the reservoir has reached a certain capacity (dependent on model), the fill cycle begins. The fill speed has a direct impact on the final haematocrit achieved; slower fill speeds result in higher RBC densities allowing better "packing" of RBCs and a higher haematocrit. Collected blood with the anticoagulant mixture will be transferred into the centrifuge bowl and "spun down" to separate the RBCs from the nonerythrocyte components (supernatant). Some machines empty the reservoir automatically, others require initiation. The centrifuge bowl fills from the bottom (via the red line) as the pump transfers the collected blood from the reservoir. As the centrifuge "spins" and separates the various components of blood into vertical concentric columns depending on their relative density, the RBCs move to the outer wall while the supernatant and irrigation fluid are forced into the centre. A "buffy coat" develops on the surface of the RBCs which contains platelets and white blood cells. The centrifuge bowl will continue to fill from the reservoir until the RBC column reaches a level sensor within the centrifuge bowl. As the centrifuge bowl continues to fill with RBC, the unwanted components, including air, are forced out the centrifuge via the effluent tubing into the waste bag, leaving the RBCs in the centrifuge bowl with some unwanted contaminants that are removed by washing, e.g. fibrinogen, bacteria, fat, anticoagulant, activated WBCs. ${ }^{4}$

This process may be likened to clothes in the washing machine. The washing machine drum is the centrifuge bowl, the clothes are the RBCs, the water is the supernatant and the clothes and water together make up whole blood. The centripetal force that is generated as the drum spins pushes the clothes around in a circle and they move to the outer edge along the drum wall as they are heavier than the water. The clothes continue their uniform circular motion while the water continues in a straight line as there is no force acting on it. As the water continues in a straight line, it goes straight out the drum holes into the drain. ${ }^{6}$
Step 4: Washing and resuspension ${ }^{1,3,7,8}$ (Figure 2C and 2D)

Washing can occur concurrently with separation using isotonic saline. The correct washing technique removes dangerous contaminants prior to reinfusion. The wash speed and wash volume will affect the final quality of the reinfusion product; slower rates allow a more even distribution of wash through the RBC column and increase the time for contaminant removal. Optical sensors detect the RBC content and when the haematocrit reaches a minimum of $50 \%$ will initiate the washing cycle. These optical sensors allow for the clamping and unclamping of the various lines. When the wash cycle begins, the red line is clamped and the yellow line opens to allow saline (from hanging bags) to enter the centrifuge bowl via the inlet tube removing unwanted particles. Washing removes thrombogenic products to reduce the risk of coagulopathies; breakdown products of cells and their potentially harmful plasma proteins that are not removed by filtration; gross chemical and physical contaminants, free haemoglobin, activated clotting factors and platelets; and the anticoagulation solution. ${ }^{3}$ The system automatically detects the wash volume, a minimum of three times the bowl volume, which it may extend until the effluent is clear. Washing was only introduced as part of the process nearly 100 years after the initial autotransfusion practices began. ${ }^{3}$ The effluent line sensor detects adequate washing by assessing the clarity of effluent fluid. Once washing is complete, the yellow line will be clamped and the blue reinfusion line opened, the pump reverses direction and empties the centrifuge bowl via the central tube allowing $\mathrm{RBCs}$ resuspended in isotonic saline to be transferred to the reinfusion bag. The empty rate should not be higher than the fill rate. Sterile air is drawn from the waste bag back into the bowl. The next cycle begins once the centrifuge bowl is emptied.

\section{Step 5: Disposal'}

The waste products including white blood cells, clotting factors, platelets, plasma, fat, free haemoglobin and excess saline and anticoagulant are collected in a waste bag.

\section{Step 6: Cell salvage and reinfusion ${ }^{1,8}$}

The resuspended, washed $\mathrm{RBC}$ are collected in a bag at room temperature which can be reinfused. A typical yield will retrieve $50-95.8 \%$ RBCs with a final haematocrit of $50-70 \%$. Cell salvaged blood must be reinfused within four hours of processing. A pressure bag should not be applied to the reinfusion bag. As a minimum, blood delivery sets with a filter of $170 \mu \mathrm{m}$ should be used, but it is preferable to use a set with a microfilter $(40 \mu \mathrm{m})$.

\section{Devices}

Some of the more commonly available devices are shown in Figure 3. The Elite ${ }^{\circledR}$ (Figure 3a), Sorin XTRA ${ }^{\circledR}$ (Figure 3b) and the autoLog ${ }^{\oplus}$ (Figure $3 \mathrm{c}$ ) use intermittent fill and wash cycles, whereas the C.A.T.S. ${ }^{\circledR}$ Plus (Figure 3d) allows for continuous centrifugation and washing and is therefore able to process smaller volumes. ${ }^{7}$

Three processing systems are available. ${ }^{2}$ The fixed volume bowl is available in a range of sizes but requires a minimum volume before processing can begin. Smaller fixed volume bowls are available for paediatrics. The variable volume disk system is able 
a

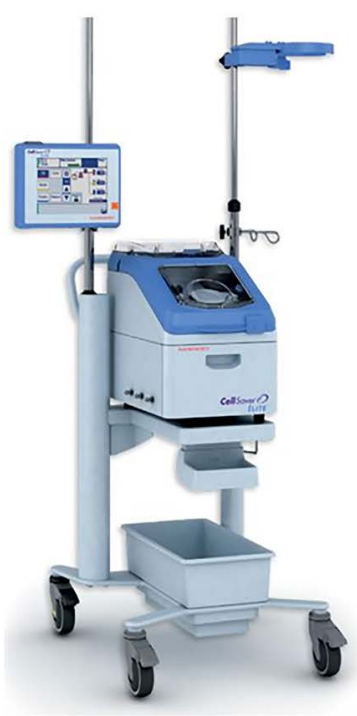

b

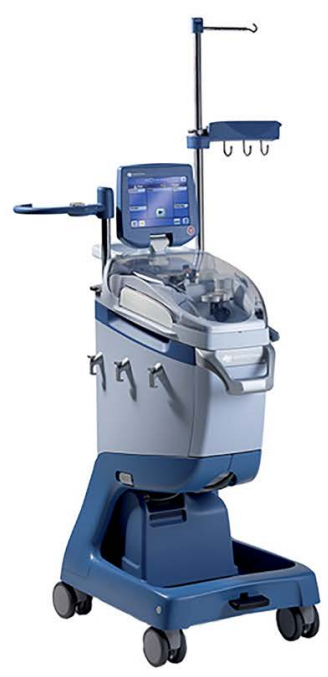

Figure 3: Commonly used cell salvage devices

to process as little as $100 \mathrm{ml}$ of reservoir contents. The system will continue to concentrate further batches of reservoir contents before washing. With the continuous rotary systems, washing and processing occur continuously producing a final product with a higher haematocrit. The washing chamber is independent of the volume and therefore very small volumes of RBC are required $(15-30 \mathrm{ml})$.

\section{Indications and contraindications $s^{2,7,11,12}$}

The indications, relative contraindications and absolute contraindications are listed below.

\section{Indications for cell salvage use}

- Anticipated blood loss $>1000 \mathrm{ml}$ or $>20 \%$ estimated blood volume.

- Low haemoglobin preoperatively or increased risk of bleeding.

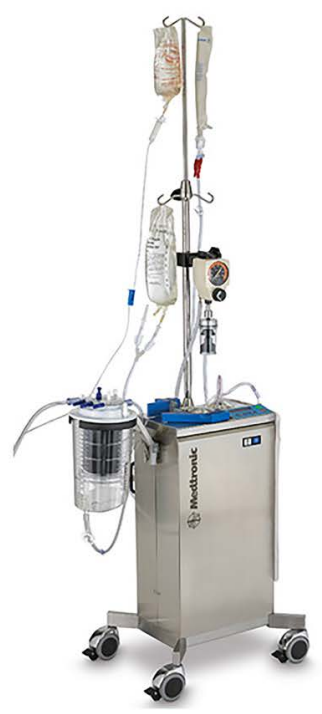

d

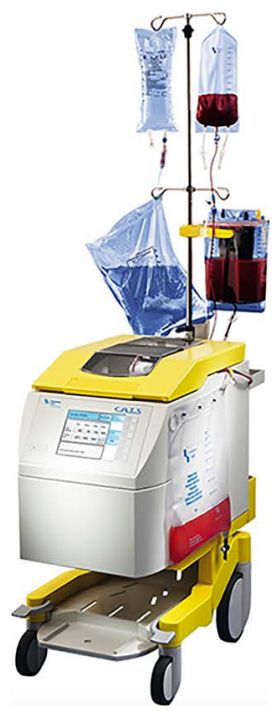

- Multiple antibodies or rare blood groups.

- Objections to receiving allogeneic blood.

- Specific types of surgery, e.g. cardiac (especially with the use of cardiopulmonary bypass), major vascular (thoracoabdominal aortic aneurysms), major orthopaedic (revision THR, pelvic surgery, spine), obstetric (abnormal placentation, multiple previous caesarean sections), liver resections and transplants, ruptured ectopic, blunt and penetrating abdominal and chest trauma, urological malignancies and selected neurosurgical cases (meningioma).

- Procedures in which $>10 \%$ of patients require transfusion.

- Cell salvage devices can be used in paediatric surgery but usually require continuous processing as opposed to a fixed volume bowl.

Table II: The advantages and disadvantages of cell salvage

\begin{tabular}{|c|c|}
\hline Advantages & Disadvantages/Complications \\
\hline Decreased demand for allogeneic blood (a scarce resource). & High initial cost of equipment and continuous cost of disposables. \\
\hline Decreased risk of transmittable diseases. & $\begin{array}{l}\text { In-service training of all theatre staff required on a regular basis, } \\
\text { especially for troubleshooting. Set-up time may cause delay. }\end{array}$ \\
\hline $\begin{array}{l}\text { Removes risk of } A B O \text { incompatibility or infusing incorrect unit. No time } \\
\text { delay required for compatibility testing. May be used if rare blood group } \\
\text { and antibodies. }\end{array}$ & $\begin{array}{l}\text { RBC damage during collection and processing, especially during } \\
\text { "skimming". }\end{array}$ \\
\hline Possible religious group acceptance, e.g. some Jehovah's Witness patients & $\begin{array}{l}\text { Bacterial contamination, e.g. colonic injuries. Risk of fat, amniotic fluid } \\
\text { and air embolus. }\end{array}$ \\
\hline $\begin{array}{l}\text { Room temperature vs fridge, reducing need for further fluid warming } \\
\text { equipment and disposables. }\end{array}$ & $\begin{array}{l}\text { Removal of clotting factors and platelets, therefore may require } \\
\text { transfusion of other blood components. }\end{array}$ \\
\hline $\begin{array}{l}\text { Near normal levels 2.3-DPG (unaltered haemoglobin-oxygen dissociation } \\
\text { curve) and more physiological levels of } \mathrm{K}+\text {. }\end{array}$ & Electrolyte imbalances. \\
\hline Avoids immunomodulating effects of allogeneic RBCs. & $\begin{array}{l}\text { Free haemoglobin scavenges nitric oxide resulting in } \\
\text { vasoconstriction, pulmonary hypertension and renal tube toxicity., } 9\end{array}$ \\
\hline \multicolumn{2}{|l|}{$\begin{array}{l}\text { Better cell membrane deformability and flexibility which may improve } \\
\text { rheology and oxygen delivery. }{ }^{13,14}\end{array}$} \\
\hline $\begin{array}{l}\text { Cost-effective when an equivalent of at least one unit of banked RBCs } \\
\text { reinfused. }{ }^{15}\end{array}$ & \\
\hline
\end{tabular}




\section{Relative contraindications}

- Pharmacological agents: clotting agents, irrigating solutions, methylmethacrylate, papaverine.

- Contaminants: urine, bone chips, fat, bowel contents, infection, amniotic fluid.

- Malignancy.

- Haematological disorders: sickle cell disease, thalassaemia.

- Miscellaneous: carbon monoxide (cautery), catecholamines (phaeochromocytoma), oxymetazoline.

\section{Absolute contraindications}

There are very few absolute contraindications. These include:

- Substances causing RBC lysis, e.g. sterile water, hydrogen peroxide, alcohol, hypotonic solutions.

- Patient refusal, e.g. Jehovah's Witness.

\section{Advantages and disadvantages ${ }^{1-3,7}$}

The advantages and disadvantages, including the complications of cell salvage are listed in Table II.

A complication known as the salvaged blood syndrome may occur. It occurs due to the activation of intravascular coagulation along with increased capillary permeability, which results in acute lung injury and acute kidney injury. It is related to the dilution of salvaged blood from large quantities of saline solution which creates deposits of cellular aggregates when used with a fixed volume bowl system. ${ }^{2,12}$

\section{Controversial issues}

Not accepting allogeneic transfusions: ${ }^{2,6,7}$ Patients can refuse allogeneic blood for personal or religious reasons, most commonly patients of the Jehovah's Witness faith. The use of cell salvaged blood is a personal decision with some Jehovah's Witness patients accept it, requiring the blood remains in continuity with the patient's own circulation. Appropriate counselling is required.

Cancer surgery: ${ }^{2,3,12,17}$ Concerns remain about reinfusing cancer cells into the bloodstream, despite studies demonstrating that cancer cells are already circulating at the time of surgery. A leucodepletion filter may remove cancer cells before reinfusion; studies show no viable tumour cells. Allogeneic transfusion holds its own risk of cancer recurrence through immunomodulation.

Bacterial contamination and bowel surgery:2,12,15,18 Cell washing with the use of a leucodepletion filter removed $99.6-100 \%$ of the bacterial load. The concurrent use of antibiotics will confer further protection. Studies conducted on abdominal trauma patients receiving autologous transfusion showed no increased risk of wound, pulmonary and urinary infection or bacteraemia.

Obstetrics:2,11,12,20 No increased risk of amniotic fluid embolism if proper methods are employed, e.g. double suction sets with a separate set to suction amniotic fluid, leucodepletion filter during reinfusion. The levels of fetal squamous cells in cell salvaged blood are comparable to the levels seen on maternal blood during placental separation. There is an increasing body of evidence confirming the safety of cell salvage in obstetrics and its use has been approved by National Institute for Health and Care Excellence (NICE), the Association of Anaesthetists of Great Britain and Ireland (AAGBI) and the Obstetric Anaesthetists' Association.

Orthopaedic surgery and fat: ${ }^{3}$ Leucocyte depletion filters remove $99 \%$ of fat particles. The clinical impact of fat embolism syndrome from reinfused cell salvaged blood seems to be small.

Sickle cell and thalassaemia:2,11,12 Manufacturers do not recommend the use of cell salvage in these conditions, although several case reports of successful use have been published. It is advised that an urgent blood smear be performed on the blood to be reinfused in order to determine the degree of sickling prior to reinfusion.

\section{Conflict of interest}

The author declares no conflict of interest.

\section{Funding source}

None.

\section{ORCID}

\section{Fourtounas (iD https://orcid.org/0000-0002-3678-018X}

\section{References}

1. Aston $D$, Rivers $A$, Dhamadasa A. Equipment in anaesthesia and critical care. Banbury, UK: Scion Publishing Limited; 2014.

2. Kuppurao L, Wee M. Perioperative cell salvage. Cont Edu in Anaesth Crit Care Pain. 2010;10(4):104-8. https://doi.org/10.1093/bjaceaccp/mkq017.

3. Konig G, Waters JH. Washing and filtering of cell-salvaged blood - does it make autotransfusion safer? Transfus Altern Transfus Med. 2012;12(3-4):78-87. https:// doi.org/10.1111/j.1778-428X.2012.01155.x.

4. Reeder GD. Autotransfusion theory of operation: a review of the physics and hematology. Transfusion. 2004;44(12 Suppl):35s-9s. https://doi. org/10.1111/j.0041-1132.2004.04181.x

5. Giancoli DC. Physics for scientists and engineers. New Jersey: Prentice Hall; 2000. https://doi.org/10.1088/0031-9120/35/5/705.

6. Woodford C. Centrifuges. 2019. Available from: https://www.explainthatstuff. com/centrifuges.html. Accessed 31 March 2020.

7. Frank SM, Sikorski RA, Konig G, et al. Clinical utility of autologous salvaged blood: a review. J Gastrointest Surg. 2020;24(2):464-72. https://doi.org/10.1007/ s11605-019-04374-y.

8. Walunj A, Babb A, Sharpe R. Autologous blood transfusion. BJA Educ.2006;6(5):192-6. https://doi.org/10.1093/bjaceaccp/mkl042.

9. Yazer MH, Waters JH, Elkin KR, Rohrbaugh ME, Kameneva MV. A comparison of hemolysis and red cell mechanical fragility in blood collected with different cell salvage suction devices. Transfusion. 2008;48(6):1188-91. https://doi. org/10.1111/j.1537-2995.2008.01670.x.

10. Waters JH, Williams B, Yazer MH, Kameneva MV. Modification of suction-induced hemolysis during cell salvage. Anesth Analg. 2007;104(3):684-7. https://doi. org/10.1213/01.ane.0000255208.96685.2e.

11. Smith C, Shippam W. Intraoperative cell salvage in obstetrics. ATOTW [Internet]. 2018. Available from: https://www.wfsahq.org/components/com_virtual library/media/6a00fa551f0ecea40b49c1dfdf40a6e8-380-Cell-salavage-inobstetrics.pdf.

12. Esper $\mathrm{SA}$, Waters $\mathrm{JH}$. Intra-operative cell salvage: a fresh look at the indication and contraindications. Blood Transfus. 2011;9(2):139-47. https://doi. org/10.2450/2011.0081-10.

13. Frank SM, Abazyan B, Ono M, et al. Decreased erythrocyte deformability after transfusion and the effects of erythrocyte storage duration. Anesth Analg. 2013;116(5):975-81. https://doi.org/10.1213/ANE.0b013e31828843e6.

14. Salaria ON, Barodka VM, Hogue CW, et al. Impaired red blood cell deformability after transfusion of stored allogeneic blood but not autologous salvaged blood in cardiac surgery patients. Anesth Analg. 2014;118(6):1179-87. https://doi. org/10.1213/ane.0000000000000227. 
15. Waters JH, Dyga RM, Waters JF, Yazer MH. The volume of returned red blood cells in a large blood salvage program: where does it all go? Transfusion.2011;51(10):2126-32. https://doi. org/10.1111/j.1537-2995.2011.03111.x.

16. Resar LM, Frank SM. Bloodless medicine: what to do when you can't transfuse. Hematology Am Soc Hematol Educ Program. 2014;2014(1):553-8. https://doi. org/10.1182/asheducation-2014.1.553.

17. Waters JH, Donnenberg AD. Blood salvage and cancer surgery: should we do it? Transfusion. 2009;49(10):2016-8. https://doi. org/10.1111/j.1537-2995.2009.02379.x.
18. Bowley DM, Barker P, Boffard KD. Intraoperative blood salvage in penetrating abdominal trauma: a randomised, controlled trial. World J Surg. 2006;30(6):107480. https://doi.org/10.1007/s00268-005-0466-2.

19. Waters JH, Tuohy MJ, Hobson DF, Procop G. Bacterial reduction by cell salvage washing and leukocyte depletion filtration. Anesthesiology. 2003;99(3):652-5. https://doi.org/10.1097/00000542-200309000-00021.

20. Allam J, Cox M, Yentis SM. Cell salvage in obstetrics. Int J Obstet Anesth. 2008;17(1):37-45. https://doi.org/10.1016/j.ijoa.2007.08.001. 